\begin{tabular}{|c|c|c|}
\hline 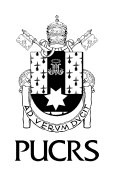 & $\begin{array}{l}\text { ESCOLA DE CIÊNCIAS } \\
\text { DA SAÚDE E DA VIDA }\end{array}$ & $\begin{array}{l}\text { Psico, Porto Alegre, v. 51, n. 2, p. 1-12, abr.-jun. } 2020 \\
\text { e-ISSN: } 1980-8623 \text { | ISSN-L: 0103-5371 }\end{array}$ \\
\hline d) $\mathrm{htp:}$ & doi.org/10.15448/1980-8623.2020.2.33744 & \\
\hline
\end{tabular}

SEÇÃO: ARTIGO

\title{
Vivências de trabalho na informalidade: um estudo com feirantes de roupas na cidade de Fortaleza-CE
}

\author{
Working experiences in informality: a study with clothing fairs in the city of Fortaleza-CE \\ Vivencias de trabajo en la informalidad: un estudio con feriantes de ropa en Fortaleza-CE
}

\section{Renata Guimarães de Carvalho $^{1}$ \\ orcid.org/0000-0002-3592-7709 \\ renatagui74@yahoo.com.br}

\section{Regina Heloisa Maciel $^{2}$} orcid.org/0000-0003-2933-7021 reginaheloisamaciel@gmail.com

\section{Tereza Gláucia Rocha \\ Matos $^{2}$ \\ orcid.org/0000-0003-0557-5340 \\ terezamatos@unifor.br}

\section{Cássio Adriano Braz de Aquino $^{1}$}

orcid.org/0000-0001-8651-1634

brazdeaquino@gmail.com

Recebido em: 29 mar. 2019. Aprovado em: 6 dez. 2019 Publicado em: 4 set. 2020.

\section{(c) (1)}

Artigo está licenciado sob forma de uma licença Creative Commons Atribuicão 4.0 Internacional.
Resumo: O objetivo deste artigo é descrever e analisar vivências de trabalho de feirantes de roupas que atuam na informalidade, em uma feira na cidade de Fortaleza-CE. Trata-se de uma pesquisa qualitativa que fez uso de observação direta e de entrevistas na coleta de dados, e da técnica de análise de conteúdo. Foram entrevistadas 17 feirantes que atuavam na comercialização de produtos e sem vinculo formal de emprego. Como resultado, identificaram-se trajetórias laborais marcadas pela informalidade e pela precarização. As vivências de trabalho apresentam aspectos positivos, como a renda obtida, a sensação de liberdade e a flexibilidade de tempo, e negativos, como o desconforto pelo periodo de funcionamento da feira e o cansaço. Amizade, confiança e ajuda reciproca compõem seus cotidianos, assim como a concorrência. Evidencia-se que as vivências relatadas são permeadas por ambivalências que, entretanto, não são suficientes para ensejar o desejo de mudança de ocupação.

Palavras-chave: trabalho, trabalho informal, subjetividade.

Abstract: This article aims to describe and analyze the work experiences of clothes merchants, that work informally in Fortaleza, Brazil, street market. It is a qualitative research that uses direct observation and interviews as data, and content analysis as a technique for interpretation. In total, 17 street merchants operating directly in the marketing of products without a formal working contract were interviewed. The results showed labour trajectories marked by informality and precariousness. Work experiences of the informal merchants have positive features, as the income obtained, feelings of freedom and flexibility of time, and negative, as the discomfort related to the market operation hours and tiredness. Friendship, trust and reciprocal aid compose merchant's daily life, as well as competition. It is evidenced that the experiences reported are permeated by an ambivalence which, however, are not sufficient to lead to the desire to change occupation.

Keywords: work, informal work, subjectivity.

Resumen: El objetivo de este artículo es describir y analizar vivencias de trabajo de feriantes que actúan en la informalidad, en un mercado de ropa en la ciudad de Fortaleza, Brasil. Es una investigación cualitativa con uso de observación directa y de entrevistas, y de la técnica de análisis de contenido. Se entrevistaron 17 feriantes que actuaban en la comercialización de productos y sin vinculo formal de empleo. Como resultados, se identificaron trayectorias laborales marcadas por la informalidad y precarización. Las vivencias de trabajo presentan aspectos positivos, como la renta obtenida, sensación de libertad y flexibilidad de tiempo, y negativos, como el período de funcionamiento de la feria y cansancio. La amistad, la confianza y las ayudas reciprocas componen su cotidiano, así como la competencia. Las vivencias relatadas están impregnadas por ambivalencias que, sin embargo, no son suficientes para dar lugar al deseo de cambio de ocupación. Palabras clave: trabajo, trabajo informal, subjetividad. 
O presente artigo trata das vivências de trabalho de feirantes de roupas que atuam no âmbito da informalidade. Considerando a expressiva parcela de trabalhadores na informalidade no Brasil, segundo dados do Instituto Brasileiro de Geografia e Estatistica (IBGE, 2018) mais de $30 \%$ da força de trabalho ocupada, parte-se da premissa de que é necessário ir além dos números e buscar nas experiências vividas por esses sujeitos uma melhor compreensão das diversas nuances desse contexto.

A informalidade pode ser entendida como a ação de pessoas e de grupos que estão à margem do Estado, lutando para efetivar estratégias para satisfazer minimamente suas necessidades econômicas e sociais (Lomnitz, 2009). Abrange atividades econômicas, capitalistas e não capitalistas, que não são reguladas por regras jurídicas vigentes (Filgueiras, Druck, \& Amaral, 2004) e, na perspectiva laboral, tem como característica a ausência de contrato formal e de proteção social para os trabalhadores (Lima \& Soares, 2002).

O reconhecimento desse contexto ocorreu a partir da década de 1970, quando estudos da Organização Internacional do Trabalho (OIT) constataram a existência de um setor informal, composto por empreendimentos de baixa produtividade, criados como forma de garantir a sobrevivência de trabalhadores e suas familias, e que funcionavam à margem da economia formal de paises subdesenvolvidos. $\mathrm{Na}$ atualidade, $\mathrm{O}$ dualismo entre atividade informal e formal foi superado em direção a uma concepção mais ampla que considera o entrelaçamento de uma informalidade tradicional, constituida por autônomos e empregados sem registro em carteira, e uma nova informalidade atrelada ao processo de reorganização da produção e flexibilização de contratos que geram empregos disfarçados e formas de trabalho mais precárias como a terceirização e as falsas cooperativas (Krein \& Proni, 2010).

Desse modo, o trabalho vivido na informalidade associa-se ao processo de precarização e de flexibilização laboral (Antunes, 2011; Filgueiras et al., 2004). A precarização pode ser entendida como um movimento sistemático de desregulação das relações laborais e das perda de direitos trabalhistas e previdenciários, integrando o movimento de reestruturação produtiva capitalista. Pode incluir situações laborais atípicas e em condições mais precárias, tendo como referência o padrão tradicional de emprego, assim como formas não assalariadas próprias da economia informal (Galleazzi, 2006). Toma-se a noção de nova informalidade, associada à precarização laboral, como referência para compreensão das vivências dos trabalhadores neste artigo.

O tema da informalidade tem sido estudado do ponto de vista da dificuldade de acesso ao emprego formal e exaustiva jornada laboral, especialmente no caso de experiências de mulheres ambulantes (Garcia et al., 2010) e catadores de recicláveis (Braga, Lima, \& Maciel, 2015). Para trabalhadores que atuam no espaço da rua, sobressaem a precariedade das condições de trabalho, a incerteza e a ênfase em estratégias de sobrevivência imediata (Durães, 2014). Relatos de dor e desconforto físico são comuns entre feirantes de roupas e não implicam na interrupção de sua atividade para tratamento ou descanso (Carvalho, Oliveira, Maia, Maciel, \& Matos, 2016). Existem ações que revelam empenho para reunir forças e melhorar a situação de trabalho, como no caso de trabalhadores que se unem em redes socioprodutivas para viabilizar a realização de atividades de geração de renda (Santos, Maciel, \& Sato, 2014), ou quando formam redes de significados em uma feira livre e criam um modo próprio de organização (Sato, 2012).

De modo geral, esses elementos também fazem parte do cotidiano de trabalhadores informais de outros paises latino-americanos (Morató, 2015; Ramírez \& Tunal, 2016; Souza \& Bustos, 2017). Um recente estudo publicado pela Organização Internacional do Trabalho (OIT) revela que apesar de uma significativa tendência de formalização do trabalho na América Latina entre 2005 e 2015, os números relativos à informalidade ainda superam 50\% do total de trabalhadores (Salazar-Xirinachs \& Chacaltana, 2018). Ademais, considerando o que dizem os autores, essa 
tendência foi possivel graças a uma combinação de transformações econômicas integradas a intervenções institucionais e políticas. Os fatos mais recentes, com alterações dessas premissas nos paises da região, denotam um recrudescimento dessa direção. O Fórum Econômico Mundial, em publicação de 2017, chamava atenção para o fato de que a informalidade latino-americana superava a da África Subsaariana e mantinha, dessa forma, os traços de baixos índices de proteção social e laboral.

Esse contexto gera desafios e possibilidades de pesquisa para a psicologia do trabalho que, de forma predominante, tem desenvolvido seus estudos a partir da noção tradicional de emprego, colocando em menor evidência temas como desemprego e trabalho informal (Sato, 2013). Assim, assume-se neste artigo a abordagem da psicologia social do trabalho, que propõe estudar as dimensões subjetivas do trabalho a partir de seus contextos micro e macrossocial, considerando as características objetivas das condições laborais e buscando dar voz e relevância aos trabalhadores (Sato, Coutinho, \& Bernardo, 2017).

Tendo em vista esses elementos e reconhecendo que cada situação laboral apresenta singularidades, têm-se como objetivo nesse artigo descrever e analisar vivências de trabalho construidas por feirantes de roupas que atuam na informalidade em um galpão de uma feira na cidade de Fortaleza-CE.

A feira onde está o galpão faz parte da tradição nordestina de organização de espaços públicos para o comércio popular e insere-se no movimento de surgimento de grandes feiras de confecções que iniciam seu funcionamento no periodo da madrugada e agregam milhares de trabalhadores informais (Lima \& Soares, 2002). Envolve diversos espaços da rua e de galpões localizados na região central da cidade de Fortaleza, nas imediações da Catedral Metropolitana, por isso sendo conhecida como feira da Sé, onde são comercializados produtos de confecção feminina, moda infantil, masculina e calçados, a chamada "modinha". Agrega amplos polos de produção e de venda de mercadorias a preços baixos, caracterizando um local de comércio popular bem conhecido. A feira passou por um amplo processo de requalificação gerenciado pela prefeitura no ano de 2017, impondo grandes modificações em sua estrutura, como a limitação das vendas nas ruas e o recadastramento de galpões (Cavalcante, 2017).

\section{Método}

Esta é uma pesquisa qualitativa, com abertura para a emergência de categorias no processo de investigação, em uma relação interativa entre pesquisador e participantes. Seguindo o delineamento qualitativo, acompanha o referencial do construcionismo social, partindo da ideia de que os significados sobre processos e objetos são construidos pelos sujeitos na interação social (Silverman, 2009).

Participaram da pesquisa 17 feirantes de roupas que exerciam sua função em bancas inseridas em um galpão coberto localizado na região da feira da Sé. Buscou-se a participação de trabalhadores que desempenhassem a função de feirante, comercializando produtos caracteristicos da feira pesquisada, excluindo-se aqueles que atuassem em outras funções como carregadores, por exemplo, e que tivessem contrato de emprego formal. A amostra foi constituída por conveniência, a partir da disponibilidade de participação, e seguiu o princípio de saturação, que indica que a coleta deve ser encerrada quando os dados obtidos se tornam redundantes.

Todos os participantes foram mulheres, o que não foi uma escolha intencional, mas resultante da grande participação feminina na feira, o que reflete a significativa inserção feminina na informalidade, principalmente no trabalho por conta própria (Araújo \& Lombardi, 2013). A faixa etária das participantes variou entre 20 e 56 anos, com média de 34 anos de idade. A maioria (10) se declarou casada ou com relação estável e com escolaridade de nível médio (11). A média de tempo de trabalho como feirante de roupas era de 7 anos e, como feirante no galpão pesquisado, de 4 anos. A remuneração mensal auferida por meio do trabalho variou entre $R \$ 600,00$ e $R \$ 7.800,00$ (menos de um e mais de oito salários mínimos da 
atualidade). Feirantes com maior renda eram donas do ponto de sua banca (12) enquanto aquelas com menor renda atuavam apenas como vendedoras (5) e eram remuneradas pelo dia trabalhado.

Como técnica de coleta de dados fez-se uso de entrevistas (Silverman, 2009). As participantes foram abordadas em seu ambiente de trabalho no galpão, em um horário de menor movimento de clientes, já próximo ao horário de fechamento da feira. Solicitou-se que respondessem às questões relacionadas ao seu perfil sociodemográfico laboral para, em seguida, abordar temas como trajetória laboral, processo de inserção na feira, rotinas e vivências do trabalho como feirantes. Os relatos foram registrados por meio de áudio e transcritos, considerando-se elementos da fala coloquial. Para garantir o anonimato das participantes foi utilizada a letra F seguida de um número para sua identificação. Utilizouse também observação para identificação de condições de trabalho e de formas de interação social no espaço da feira. Para registro dos dados foram utilizadas notas de campo (Gibbs, 2009).

No tratamento dos dados aplicou-se a análise de conteúdo, especificamente a categorial temática, envolvendo a organização de unidades por meio de temas, posteriormente classificados em categorias. Na perspectiva adotada, o foco foi a presença ou a ausência de unidades de análise nas categorias e não sua frequência ou quantidade (Bardin, 2011). O programa Atlas. ti foi utilizado como recurso complementar na organização dos dados (Gibbs, 2009).

A pesquisa seguiu as resoluções n. 466/12 e n. 510/16 do Conselho Nacional de Saúde, tendo passado por aprovação de Comitê de Ética em Pesquisa da Universidade de Fortaleza (Unifor). As participantes foram esclarecidas sobre as características da pesquisa, objetivos, riscos e benefícios, e concordaram em participar e assinar o Termo de Consentimento Livre e Esclarecido.

\section{Resultados e discussão}

No processo de análise qualitativa foram estabelecidas categorias pertinentes ao objetivo do estudo. Em "caminhos até a feira", teve-se o intuito de conhecer a trajetória laboral das entrevistadas e sua inserção na feira de roupas. Em "sendo feirante" são descritas as vivências de trabalho. Finalmente, em "laços, trocas e normas" são enfatizados os vínculos construidos e as normas de convivência. Buscou-se dar voz às feirantes durante toda a análise de dados e, para isso, foram escolhidos trechos de suas falas considerados mais representativos de suas vivências em cada categoria.

\section{Caminhos até a feira}

Entre as entrevistadas identificou-se duas formas principais de trajetória laboral. Há aquelas que começaram a trabalhar ainda muito jovens, em atividades ligadas à feira de roupas, por forte influência das relações familiares, e já imersas na informalidade. Atuavam em pequenos serviços, como auxilio nas costuras ou nas vendas. A feira de roupas foi sua primeira e, muitas vezes, única experiência de trabalho, tendo passado por várias delas até assumir sua função de maneira independente, como relatado: "(...) a gente começou desde pequena no acabamento, cortando as pernas de linhas. Depois, quando a gente foi crescendo, a gente foi ajudando ela (a mãe) nas vendas e aí quando eu fiquei de maior, eu já fui sozinha" (F9, comunicação pessoal, 25 Jun. 2015).

Nesse caso, a inserção no ofício de feirante e na informalidade foi um caminho natural, mas não necessariamente fruto de uma escolha consciente. De forma semelhante, ao abordar a inserção de familiares de feirantes na feira livre, Sato (2012, p. 151) ressalta que se tratava "de uma trajetória que se apresenta como possivel, viável e inquestionável para muitos".

Por outro lado, há trajetórias marcadas por intensa mobilidade, alternando períodos com e sem trabalho assalariado formal, como descrito na fala a seguir: "Meu primeiro trabalho foi em uma escola (...) depois fui trabalhar em lanchonete (...). Aí, depois, me convidaram para trabalhar num plano funerário (...) lá eu tive carteira assinada e tudo, só que eu só passei 6 meses" (F15. comunicação pessoal, 16 Jul. 2015).

Esse perfil se insere no panorama de 
instabilidade e insegurança que é caracteristico do processo de precarização atual. Os trabalhadores menos qualificados vivenciam uma rotatividade quase obrigatória, sobrevivendo entre empregos precários com baixa remuneração. Nessa conjuntura, uma mesma pessoa pode passar pelo emprego formal, informal ou mesmo desemprego em um curto período de tempo, ampliando sua incerteza frente às contingências presentes e futuras (Castel, 2005). Em sua maioria, as entrevistadas atuaram em ocupações que não exigiam uma qualificação profissional específica, como é próprio de parcelas de trabalhadores que transitam na informalidade (Krein \& Proni, 2010).

Esses dados se articulam com as expectativas que impulsionaram a busca do trabalho como feirante, como mostram as seguinte falas: "O desemprego tá muito grande, (...) às vezes, algumas pessoas vão em busca de trabalho, não encontram e aí: 'ah eu vou fazer alguma coisa pra mim vender na feira', porque tá difícil emprego (F7, comunicação pessoal, 25 Jun. 2015); "Na verdade, eu vim buscar mais essa questão de não ter mais patrão. Trabalhar pra mim mesmo e crescer (...), degrau por degrau" (F14, comunicação pessoal, 16 Jul. 2015); e "Todo mundo quer ter alguma coisa na vida, quer crescer. Tem gente que tem, que consegue, tem muitos que não conseguem. É assim, uns querem, vai quebrando, vai saindo, vai entrando os novos e assim vai" (F6, comunicação pessoal, 25 Jun. 2015).

A necessidade de trabalhar, ter um sustento, e a expectativa de obter um meio de sobrevivência alternativo ao emprego, expressa a dificuldade de inserção no mercado formal que acompanha muitos trabalhadores na informalidade (Braga et al., 2015; Correia, Pereira, \& Carrieri, 2018; Garcia et al., 2010). Além disso, existe a vontade de ter um negócio próprio, não ter patrão, e a aposta na possibilidade de crescimento, de melhoria de vida e de aquisição de bens materiais. A prosperidade financeira, entretanto, não chega para todos. A fala de F6 descreve essa engrenagem que movimenta a feira e que implica na dinâmica de atração e de exclusão de trabalhadores. As feirantes entendem que há um risco inerente à sua atividade, mas isso não gera um sentido negativo específico, já que desde sua trajetória laboral convivem com processos de instabilidade e insegurança. Essa predisposição ao risco remete também à influência da cultura do empreendedorismo, enquanto modo individualista e alternativo ao desemprego, que forja um sentido positivo ao trabalhador na informalidade, nessa perspectiva, um empreendedor por necessidade (Lima, 2010).

Movidas por essas expectativas, as entrevistadas buscam o trabalho como feirante e, para isso, contam com a ajuda de pessoas que já tinham algum contato ou trabalhavam diretamente na feira: "Foi porque falaram que estavam precisando, né? E o meu vizinho já trabalhava pra eles aí eu vim gostei, ai fiquei" (F4, comunicação pessoal, 25 Jun. 2015) e este outro trecho de discurso:

Meu esposo começou a vir na feira (...) Ai um certo dia ele disse assim: "Filha, eu vou precisar de alguém pra trabalhar comigo", eu disse pra ele "O quê? Você vai chamar outra pessoa? Vai não, vai de jeito nenhum, eu vou com você". (F15. comunicação pessoal, 16 Jul. 2015).)

Especialmente entre as entrevistadas que eram donas de banca, observou-se a influência decisiva de membros da familia que já atuavam em feiras de roupas e contavam com esposas, filhas e noras para suporte em sua atividade. Nota-se aí que o vínculo familiar pode ser um estímulo determinante não só na inserção, mas na permanência de trabalhadores na informalidade (Correia, Pereira, \& Carrieri, 2018; Lima \& Conserva, 2006; Morató, 2015; Xavier, Falcão, \& Torres, 2015). Entre as feirantes que eram vendedoras contratadas em uma banca, identificou-se a predominância da indicação de amigos e vizinhos para obtenção do posto de trabalho, indicando que a inserção na feira acontece prioritariamente por intermédio de relações interpessoais.

As dificuldades iniciais do trabalho estão, em geral, relacionadas à adaptação ao seu periodo de realização, que exige que os feirantes acordem de madrugada, "no melhor do sono", e, também que trabalhem durante o final de semana: "Começo eu sofri bastante (...). Sofri porque não tinha o costume de me acordar de madrugada. Ainda passei um 
ano sofrendo. Ai hoje em dia eu estou acostumada" (F2, comunicação pessoal, 25 Jun. 2015).

Considerando a trajetória laboral e a inserção na feira, pode-se identificar que as histórias das feirantes trazem o trabalho como um elemento central, que perpassa suas familias e modos de vida, apesar da precariedade. É a busca pelo trabalho e, talvez, um trabalho mais digno, que leva as entrevistadas até a feira.

\section{Sendo feirante}

O dia a dia de trabalho das feirantes começa muito cedo, como descrito nas falas a seguir: "A gente chega três horas da manhã e vai embora meio dia. (...) Aí a gente tira a mercadoria, arruma (...) por modelos (...). A gente tranca a banca porque a mercadoria fica pra próxima feira" (F1, comunicação pessoal, 25 Jun. 2015).

A feira de roupas acontece quatro dias por semana e tem início ainda de madrugada. $O$ trabalho começa com o transporte de mercadorias, tarefa realizada com a ajuda da família ou de carregadores contratados. A estrutura das bancas é bastante simples: dispõem de um armário para guardar mercadorias e alguns materiais como sacos plásticos, manequins para exposição dos produtos, banco ou cadeira para descanso em momentos de menor fluxo.

As feirantes escolhem as peças que vão ficar expostas, vestem os manequins e aguardam os compradores que chegam ao galpão ainda antes do nascer do sol. Os clientes são geralmente sacoleiros que vem de outras cidades em ônibus fretados e têm tempo limitado para efetivar uma grande quantidade de compras. Essa necessidade de celeridade no atendimento gera uma sobrecarga, principalmente para feirantes que trabalham sozinhos. Por volta de onze horas da manhã o fluxo de clientes é bem menor e já se inicia o fechamento das bancas.

A partir das práticas de trabalho, das necessidades e oportunidades de atuação, os feirantes da feira da Sé desenvolveram modos diferenciados de ser feirante (Carvalho et al., 2016). Assim, o feirante-fabricante é aquele que produz e vende suas mercadorias em sua própria banca; o feirante-comerciante atua apenas na comercialização de produtos; e o feirante-vendedor é o trabalhador contratado por proprietários de banca para atender clientes e efetivar vendas, sendo remunerado por diária. Entre as entrevistadas foram identificadas feirantes fabricantes e comerciantes, todas donas de banca, e vendedoras, o que explica a variabilidade da renda apontada pelos dados sociodemográficos e diferenças em algumas vivências de trabalho.

Sobre as vantagens do trabalho, entre as donas de banca predomina a vivência de liberdade por não ter patrão, além da ideia de benefício financeiro e da circulação rápida de dinheiro a cada dia de feira, já que as vendas acontecem à vista. Para as feirantes que atuam como vendedoras, prevalece também a sensação de liberdade por ser um ambiente considerado de menor pressão e onde a renda obtida é compativel com o trabalho realizado. Isto pode ser ilustrado pelas seguintes falas: "É mais gratificante quando a gente trabalha pra gente do que mesmo pra uma pessoa, né? (...) nós não temos patrão pra tá dando ordem, né?" (F7, comunicação pessoal, 25 Jun. 2015); "Bom, pra mim a vantagem é: você tem seu próprio negócio, você não depende de ninguém, você, entre aspas, vai a hora que quer, entre aspas porque o dia que você não for, você não ganha" (F14, comunicação pessoal, 16 Jul. 2015); e "(...) a renda compensa" (F1, comunicação pessoal, 25 Jun. 2015).

A busca por autonomia e independência faz parte da experiência de trabalhadores informais em outros estudos (Correia, Pereira, \& Carrieri, 2018; Garcia et al., 2010; Ramírez \& Tunal, 2016; Santos \& Mesquita, 2016). Embora essa autonomia gere riscos, como a variabilidade de ganhos, acredita-se que a renda auferida na informalidade seja maior do que a obtida em um emprego formal (Sasaki \& Menezes, 2012). Essa ideia se contrapõe a dados que apontam que, de forma geral, os trabalhadores formais têm maior remuneração do que os informais (Araújo \& Lombardi, 2013).

A possibilidade de uma melhor organização do tempo também é considerada uma vantagem para donas de banca e vendedoras: "A gente vai embora meio dia, dá pra fazer até de tarde outras 
coisas, dá pra fazer um curso, trabalhar em outra empresa, quem tem pique, né?" (F5, comunicação pessoal, 25 Jun. 2015).

O periodo e o horário de funcionamento da feira são considerados favoráveis, pois possibilitam a organização do tempo a partir das necessidades de cada um. Pode-se inferir que essas vantagens fazem sentido se comparadas com experiências anteriores em uma jornada de trabalho padrão, quando se trabalha cinco dias por semana durante todo o período do dia. Esses dados se alinham ao proposto por Araújo e Lombardi (2013), que apontam para a falta de padronização e mais flexibilidade dos tempos de trabalho na informalidade, se comparados às ocupações formais.

A movimentação na feira, que possibilita conhecer pessoas diferentes e formar amizades, também é ressaltada como algo positivo pelas entrevistadas de maneira geral. Esse dado se relaciona ao processo de formação de laços, especialmente de amizade, entre as trabalhadoras e também com clientes. Esses sentidos positivos do trabalho na feira são similares ao de mulheres ambulantes que entendem como vantagens a flexibilidade de horários e a diversidade de contatos pessoais (Garcia et al., 2010).

Sobre as desvantagens experimentadas há a prevalência de dificuldades relacionadas com o horário de funcionamento da feira e o trabalho aos finais de semana: "É a noite de sono que a gente perde" (F1, comunicação pessoal, 25 Jun. 2015); "(...) a gente acorda cedo, chega de madrugada e não tem tempo pra sair pra nenhum canto, a feira é sábado e domingo, é o final de semana que a gente tem pra sair pra algum canto" (F2, comunicação pessoal, 25 Jun. 2015); e "(...) você tem que abandonar sua familia e seu filho (...) porque você tem que trabalhar, você tem que ir em busca da sua profissão, da sua estabilidade, quem é autônomo, né?" (F7. comunicação pessoal, 25 Jun. 2015).

Além de ser necessário acordar de madrugada, por volta das duas da manhã, é preciso trabalhar no fim de semana, fazendo com que os feirantes percam um período de lazer e convivência familiar que consideram importante, o que gera sensação de desgaste. Esses relatos reforçam aspectos já apresentados no processo de inserção na feira, principalmente relacionado aos horários de trabalho, indicando que o desconforto vivenciado na entrada na feira permanece apesar dos esforços de adaptação e que, o trabalho na informalidade, exige sacrificios relacionados às vivências em outras esferas da vida.

A atividade é considerada muito cansativa. O fato de permanecer muito tempo em pé ou sentado em pequenos bancos sem encosto, aumenta a sobrecarga física. Um elemento percebido por meio da observação direta foi a circulação de vendedores ambulantes dentro do galpão oferecendo spray para alívio de dor muscular, o que é um indício do incômodo experimentado. Observou-se, ainda, feirantes dormindo dentro de armários que servem de depósito para as mercadorias. Identificase ai um trabalho penoso pela necessidade de longas jornadas em situações de trabalho desconfortáveis, dado similar ao encontrado em pesquisa com camelôs (Santos \& Mesquita, 2016).

As condições ambientais do galpão são bastante desagradáveis. O mesmo foi montado na estrutura de um antigo estacionamento, abaixo do nivel da rua, o que prejudica a ventilação. Com climatização feita por grandes ventiladores, a área das bancas é, ainda assim, abafada e quente, como pode ser verificado por meio de observação direta. Esses elementos reforçam a constatação de que o trabalho na informalidade, mesmo em sua heterogeneidade de práticas, insere os trabalhadores em condições prejudiciais à sua saúde e segurança (Bernardino \& Andrade, 2015; Krein \& Proni, 2010).

Apesar das adversidades, as entrevistadas relataram gostar de sua ocupação e a intenção de permanecer na atividade, dado encontrado também entre ambulantes que atuam em praia em Natal-RN (Xavier et al., 2015) e entre ambulantes na Cidade do México (Ramirez \& Tunal, 2016). Vendedoras narraram que dali só sairiam para montar sua própria banca, movimento já efetivado por outras feirantes que começaram como diaristas e viraram donas de bancas. Outras desejam ampliar seu negócio, abrindo uma pequena loja no galpão e contratando funcionários. As falas que ilustram o quanto gostam do que fazem podem ser vistas nos seguintes trechos: "Amo (...) eu não 
saio daqui não" (F6, comunicação pessoal, 25 Jun. 2015); "Adoro, adoro meu trabalho (...) daqui só trabalhar pra mim mesma" (F4, comunicação pessoal, 25 Jun. 2015) e:

(...) você sempre tem que olhar pelo lado bom, porque se você for olhar pelo lado ruim, você sempre vai ficar estressada, mal-humorada (...) então, você tem que tá sempre com um sorriso no rosto, por mais que você tenha alguma dificuldade. (F15, comunicação pessoal, 16 Jul. 2015)

O sonho de trabalhar na feira e mudar de vida, ter o seu próprio negócio ou a expectativa de um dia chegar lá, submete muitos feirantes a condições precárias. Há uma tentativa de superar as dificuldades e permanecer em sua atividade. atitude também encontrada em outras situações de informalidade, como entre os catadores de recicláveis (Braga et al., 2015).

De maneira geral, as vivências de trabalho das feirantes, sejam elas donas de banca ou vendedoras, contemplam sentidos que são permeados por ambivalências que nascem do confronto entre expectativas positivas e a dura realidade de trabalho no dia a dia da feira. Tanto donas de banca quanto vendedoras se submetem às mesmas condições laborais e à mesma rotina de trabalho no galpão: há a democratização das possibilidades de risco e de desconfortos.

Se por um lado o horário de término da feira gera a noção de tempo livre, é necessário começar o trabalho de madrugada, o que causa desconforto. Pode-se dispor do período da tarde, mas como ressalta F5, isso é para quem tem "pique" e suporta o cansaço. Além disso, a liberdade vivenciada por não ter patrão se choca com a necessidade de obtenção de renda, exigindo o aproveitamento de todos os dias de realização da feira e as oportunidades de venda, intensificando o trabalho e a sensação de cansaço.

Um olhar para o futuro, só que um futuro distante, vislumbra um periodo em que já não se tenha resistência física para o trabalho na feira: "(...) eu sei que vai chegar um tempo que eu não vou poder mais trabalhar, então eu vou ter que ter uma renda, como eu nunca trabalhei de carteira... (...) Daqui mais uns 15 anos, né?" (F17, comunicação pessoal, 16 Jul. 2015).

Os planos relatados envolvem ter uma reserva financeira ou ir comprando casas para viver de aluguéis na velhice, já que não se pensa em recorrer à previdência social. Dado semelhante foi encontrado entre trabalhadores por conta própria que consideram mais vantajoso financeiramente permanecer na informalidade e adquirir imóveis para ter uma renda futura (Sazaki \& Menezes, 2012).

\section{Laços, trocas e normas}

Além dos vinculos familiares, é necessário o estabelecimento de laços de amizade para um bom desempenho na feira: "(...) aqui eu me dou com todo mundo, aqui todo mundo é amigo. Graças a Deus aqui nunca tive confusão. Só amizade, bastante amizade" (F2, comunicação pessoal, 25 Jun. 2015).

Em um ambiente tão dinâmico e competitivo, é preciso manter a sensação de segurança entre os clientes, permitindo que as trocas comerciais aconteçam com um mínimo de estabilidade para atrair o maior número possivel de compradores. Ter amizade também é fundamental para a prestação de pequenos favores, como cuidar da banca de um vizinho, evento bastante comum no cotidiano da feira, como foi possivel apreender por meio da observação direta. Os laços familiares que inicialmente ajudam na inserção e na organização do trabalho informal precisam ser ampliados em direção aos colegas de ofício, tornando necessária a formação de laços de amizade (Lima \& Conserva, 2006).

Associada ao estabelecimento dessas relações está a confiança e a reciprocidade: "(...) pra fazer amizade aqui? Precisa confiança" ( $F 13$, comunicação pessoal, 16 Jul. 2015); (...) Claro, tem que confiar, porque é um elo que a gente tem que ter, né? (F15, comunicação pessoal, 16 Jul. 2015); e

Todos eles ajudam. Se eu for lá no banheiro e disser assim: olha ai a banca, eles olham. Até vende a mercadoria porque eles sabem os preços, vende e chega e entrega o dinheiro. E assim eles fazem na minha e eu faço na deles quando eles precisam. (F17, comunicação pessoal, 16 Jul. 2015) 
A confiança e o sentido de reciprocidade fazem parte de normas de convivência imprescindiveis na construção e no desenvolvimento dos laços entre feirantes. Todos contam com a ajuda, principalmente, do vizinho de banca, e estão prontos também para retribuir no que for necessário. A regra básica de reciprocidade estabelecida por Mauss (2013), a triplice obrigação de dar, receber e retribuir, é um modo de conduta usual entre feirantes, aumentando a estabilidade das relações e potencializando a criação de novos vínculos necessários à realização do trabalho. Souza e Bustos (2017) identificaram dados semelhantes ao ressaltar a formação de redes de apoio e de solidariedade entre trabalhadores informais nas ruas do Chile.

Seguindo a lógica argumentativa de Lomnitz (2009) e de Castel (2005), considera-se que sujeitos inseridos em situação de insegurança, sem a proteção social baseada nos direitos avalizados pelo Estado, como no trabalho informal, podem retomar práticas tradicionais de garantia social, baseadas na rede próxima de proteção ofertada por laços familiares, de amizade, confiança e reciprocidade. Esses elementos estão presentes no desenvolvimento de redes socioprodutivas entre trabalhadores na informalidade, sendo um indício importante de formação de capital social (Santos et al., 2014).

Todavia, o espaço da feira é atravessado também pelas leis de mercado: compra, venda, preço, demanda, oferta e concorrência. Permeando as relações de cooperação estão também as de competição, dado já apontado por pesquisas em comércio ambulante e feira livre (Garcia et al., 2010; Lima \& Conserva, 2006; Sato, 2012; Xavier et al., 2015).

Esse lado mais obscuro da vivência das feirantes foi sendo revelado aos poucos nas entrevistas. Geralmente associado a afirmações como: "mas aqui, isso não acontece".

Os feirantes geralmente, não com essas pessoas que eu falei, graças a Deus, eu não tenho assim o que reclamar de nenhum dos meus vizinhos, mas o que gera uma confusão aqui na feira é, às vezes, a pessoa copiar um modelo da outra. ( $F$ 7. comunicação pessoal, 25 Jun. 2015)
A grande questão apontada como geradora de brigas é a prática, considerada desleal, de copiar os modelos de roupas e acessórios vendidos por outras bancas e baixar os preços tabelados informalmente. Essa atitude quebra as relações de amizade e de confiança e, principalmente, as normas de ajuda recíproca.

No curto ciclo de produção e de venda de mercadorias, que pode ser semanal e até diário, acompanhar e atender às demandas dos clientes é uma questão de sobrevivência. E criar modelos com venda garantida não é uma tarefa fácil. É necessário estar atento ao mundo da moda por meio da televisão, da internet, nas lojas de departamentos e, também, na feira. A cópia de modelos pode acontecer, contanto que seja discreta, com mudanças nos tecidos, aviamentos e detalhes da roupa. Afinal, "nada se cria, tudo se copia" (F16, comunicação pessoal, 16 Jul. 2015). Copiar os modelos como "xerox" e vendê-los a um preço mais baixo, quebrando a regra informal de padronização de preços, é causa de grande indignação entre feirantes. Ao invés das ajudas reciprocas, sobressai aí a face da competição, do individualismo, do foco imediatista no ganho, próprios da cultura do capitalismo (Castel, 2005).

Quando questionados sobre como resolviam as desavenças, as respostas eram evasivas, indicando que isso ocorria por meio de brincadeiras ou ficava "por isso mesmo": "briga, depois tá todo mundo se falando de novo. Tem essa de ficar mal não." (F6, comunicação pessoal, 25 Jun. 2015). Essa fala assinala a necessidade de manutenção de um tênue equilíbrio entre elementos contraditórios como amizade, confiança, cooperação e concorrência, em um processo de regulação coletiva permanente.

\section{Considerações finais}

A situação laboral das feirantes confirma as condições de precariedade e exclusão de direitos sociais, caracteristicos da informalidade, encontrada na literatura (Braga et al., 2015; Garcia et al., 2010; Krein \& Proni, 2010; Sasaki \& Menezes, 2012). Dentre as características mais destacadas encontradas na investigação, podem ser citadas 
as formas de subcontratação, vínculos sem qualquer formalização pautados em laços de familiaridade e redes de amizade.

Nesse contexto, há prevalência de vivências positivas sobre o trabalho, como a ideia de retorno financeiro, de autonomia e de flexibilidade de tempo. Mas também é considerado muito cansativo, submetido a horários e dias de realização que causam desconforto, e com ritmo intenso para não comprometer a obtenção de renda. Essas ambivalências expressam reconhecimento das dificuldades vividas na feira e na informalidade, como a sobrecarga de trabalho e a instabilidade, mas se associam à necessidade de superar as dificuldades e "olhar pelo lado bom" (F15, comunicação pessoal, 16 Jul. 2015), pois é preciso "ir em busca da sua profissão" (F7, comunicação pessoal, 25 Jun. 2015). As adversidades enfrentadas não são suficientes para o desejo de abandono de sua ocupação, o que pode estar indicando, indiretamente, a percepção de precariedade das condições de trabalho no contexto formal.

Um traço característico das relações entre feirantes é a existência de associações espontâneas baseadas na amizade, na confiança e nas ajudas reciprocas. Esses laços são vivenciados de forma positiva e são importante fonte de apoio na realização do trabalho no dia a dia. A competição, característica dos modos individualistas do capitalismo, também é presença constante na feira, compondo um mosaico aparentemente contraditório, mas em tênue equilibrio, necessário para a continuidade da atividade como feirante e da própria feira de roupas.

A convivência com ambivalências e contradições pode ser compreendida a partir das trajetórias laborais das feirantes, marcadas pela informalidade e pela precarização que, de certa forma, naturalizam a vivência de condições penosas. Além disso, a feira representa um lugar onde o trabalho é possivel, trabalho que organiza o tempo, provisiona rendimentos, possibilita melhoria de vida, ou pelo menos sua expectativa, e a construção de novos vínculos sociais, representando um elemento central em suas vidas. Esses aspectos não suprimem a precariedade de sua situação laboral, nem a concorrência individualista, mas apontam para experiências de trabalhadores que criam modos de vida e de trabalho próprios, longe do modelo tradicional de emprego, interagindo em meio ao tumulto, no clima abafado do galpão, e encontrando possibilidades de criação e de recriação, singular e coletiva, de seu trabalho.

Os resultados apresentados, portanto, mostram um quadro ambíguo em relação ao trabalho informal, associado à insegurança e à precariedade, mas que também possui aspectos que podem ser vivenciados de modo positivo por trabalhadores. Espera-se que as considerações feitas aqui possam ser agregadas à compreensão do trabalho no atual estágio da reestruturação produtiva e que essas reflexões possam servir de subsidio para outras pesquisas sobre o tema e para a discussão de políticas públicas na área.

\section{Referências}

Antunes, R. (2011). Os modos de ser da informalidade: rumo a uma nova era da precarização estrutural do trabalho? Serviço Social \& Sociedade, 3(107), 405-419. https://dx.doi.org/10.1590/S010166282011000300002

Araújo, A. M. C., \& Lombardi, M. R. (2013). Trabalho informal, gênero e raça no Brasil do início do século XXI. Cadernos de Pesquisa, 43(149), 452-477. https:// dx.doi.org/10.1590/S0100-15742013000200005

Bardin, L. (2011). Análise de conteúdo. São Paulo: Edições 70.

Bernardino, D. C. A. M. \& Andrade, M. (2015). O Trabalho Informal e as Repercussões para a Saúde do Trabalhador: Uma Revisão Integrativa. Revista de Enfermagem Referência, IV, n. 7 , 149-158. http://dx.doi. org/10.12707/RIV14049

Braga, N. L., Lima, D. M. A., \& Maciel, R. H. (2015). Não tinha trabalho, mas tinha reciclagem: Sentidos do trabalho de catadores de materiais recicláveis. Temas em Psicologia, 23(4), 1051-1059. https://dx.doi. org/10.9788/TP2015.4-18

Brasil. Ministério da Saúde. Conselho Nacional de Saúde. Resolução n 466, de 12 de dezembro de 2012. Diário Oficial da [da] República Federativa do Brasil, Brasilia, DF, 3 de junho de 2013. Disponivel: http://conselho.saude.gov.br/resolucoes/2012/Reso466.pdf

Brasil. Ministério da Saúde. Conselho Nacional de Saúde. Resolução n 510, de 7 de abril de 2016. Diário Oficial Brasilia, DF, 24 maio 2016. Disponivel em: http:// conselho.saude.gov.br/resolucoes/2016/Res0510.pdf 
Carvalho, R. G., Oliveira, I. A., Maia, L. M., Maciel, R. H., \& Matos, T. R. (2016). Situações de trabalho e relatos de dor entre feirantes de confecções. Revista Psicologia Organizações e Trabalho, 16(3), 274-284. https:// dx.doi.org/10.17652/rpot/2016.3.735

Castel, R. (2005). A insegurança social: O que é ser protegido? Petrópolis, RJ: Vozes.

Cavalcante, I. (2017, 11 de maio). Prefeitura ocupará José Avelino para impedir que feira continue. O Povo online. Recuperado de: https://www.opovo.com.br/jornal/cotidiano/2017/05/prefeitura-ocupara-jose-avelino-para-impedir-que-feira-continue.html (DOI INEXISTENTE)

Correia, G., Pereira, H., \& Carrieri, A. (2018). "Ser um ambulante é necessidade que nós temos de trabalhar". Cadernos De Psicologia Social Do Trabalho, 21(2), 165-180. https://doi.org/10.11606/ issn.1981-0490.v21i2p165-180

Durães, B. (2014). O trabalho de rua no Brasil: O perfil da informalidade de rua em Salvador. In R. Antunes (Org.), Riqueza e miséria do trabalho no Brasil III (pp. 233-257). São Paulo: Editora Boitempo.

Filgueiras, L. A. M., Druck, G., \& Amaral, M. F. (2004). O conceito de informalidade: Um exercício de aplicação empírica. Caderno CRH, 17(41), 211-229. Recuperado de: https://portalseer.ufba.br/index.php/crh/ article/view/18490 (DOI INEXISTENTE)

Forum Económico Mundial (2017). La economia informal de América Latina supera por primera vez la de Africa Subsahariana. Recuperado de https://es.weforum.org/agenda/2017/05/la-economia-informal-de-africa-esta-retrocediendo-mas-rapido-que-la-economia-latinoamericana/(DOI INEXISTENTE)

Galleazzi, I. (2006). Precarização do trabalho. In A. D. Cattani, \& L. Holzmann (Orgs.), Dicionário de trabalho e tecnologia (pp. 203-207). Porto Alegre: Ed. da UFRGS.

Garcia, M. R. V., Segre, A., Baccaro, A. F., Silva, L. M., Costa, L., \& Cândido, M. S. (2010). "Mulheres guerreiras": Identidade feminina e profissional entre vendedores ambulantes da cidade de São Paulo. Cadernos de Psicologia Social do Trabalho, 13(1), 27-42. https:// doi.org/10.11606/issn.1981-0490.v13i1p27-42

Gibbs, G. (2009). Análise de dados qualitativos. Porto Alegre, Artmed.

IBGE - Instituto Brasileiro de Geografia e Estatística (2018). Pesquisa Nacional por Amostra de Domicilios Contínua. Indicadores para população de 14 anos ou mais de idade. Recuperado de: ftp://ftp.ibge.gov.br/ Trabalho_e_Rendimento/Pesquisa_Nacional_por_ Amostra_de_Domicilios_continua/Mensal/Quadro_Sintetico/2018/pnadc_201806_quadroSintetico. pdf (DOI INEXISTENTE)

Krein, J. D. \& Proni, M. W. (2010). Economia informal: Aspectos conceituais e teóricos. Brasília, OIT - Escritório da OIT no Brasil. Recuperado de: http://Www. oitbrasil.org.br/node/241 (DOI INEXISTENTE)

Lima, J. C. (2010). Participação, empreendedorismo e autogestão: Uma nova cultura do trabalho? Sociologias, 12(25), 158-198. https://dx.doi.org/10.1590/ S1517-45222010000300007
Lima, J. C., \& Conserva, M. S. (2006). Redes sociais e mercado de trabalho: Entre o formal e o informal. Politica \& Trabalho - Revista de Ciências Sociais, 24. 73-98. Recuperado de: http://www.periodicos. ufpb.br/ojs/index.php/politicaetrabalho/article/ view/6602 (DOI INEXISTENTE)

Lima, J. C. \& Soares, M. J. B. (2002). Trabalho flexivel e o novo informal. Caderno CRH, 17(37), 163-180. Recuperado de https://portalseer.ufba.br/index.php/crh/ article/view/18606 (DOI INEXISTENTE)

Lomnitz, L. A. (2009). Redes sociais, cultura e poder. Rio de Janeiro, E-papers.

Mauss, M. (2013). Ensaio sobre a dádiva: Forma e razão da troca nas sociedades arcaicas. São Paulo: Cosacnaify Portátil.

Pereira Morató, R. (2015). Max Paredes, el comercio popular y la apropiación del espacio público. Tinkazos, 18(38), 35-51. Recuperado de http://WwW. scielo.org.bo/scielo.php?script=sci_arttext\&pi$\mathrm{d}=$ S1990-74512015000200003\&lng=es\&tlng=es (DOI INEXISTENTE)

Ramírez, E. \& Tunal, G. (2016). El trabajo informal de los vagoneros en el Metro de la Ciudad de México. Pensamiento Americano, 9(16), 78-109. Recuperado de: https://www.redib.org/recursos/Record/oai_articulog34374-trabajo-informal-vagoneros-metro-ciudad-mexico (DOI INEXISTENTE)

Salazar-Xirinachs, J. M. \& Chacaltana, J. (2018). Políticas de Formalización en América Latina: Avances y Desafios. Lima: OIT, Oficina Regional para América Latina y el Caribe, FORLAC. 484 p. (DOI INEXISTENTE)

Santos, D. R. \& Mesquita, A. A. (2016). Avaliação das Condições de Trabalho e Sofrimento Psíquico em Camelôs. Revista Psicologia e Saúde, v. 8, n. 2, 29-42. http://dx.doi.org/10.20435/2177-093X-2016-v8-n2(03)

Santos, J. B. F., Maciel, R. H., \& Sato, L. (2014). Trabalhadores informais e a formação de redes socioprodutivas (RSP): Considerações teórico-empíricas. Contemporânea, 4(2), 325-350. Recuperado de http:// www.contemporanea.ufscar.br/index.php/contemporanea/article/view/251 (DOI INEXISTENTE)

Sasaki, M. A. \& Menezes, I. V. (2012). Trabalhador informal e Previdência Social: o caso dos trabalhadores por conta própria de Brasília - DF. Política \& Sociedade, 11(21), 173-197. http://dx.doi.org/10.5007/ 2175-7984.2012V11n21p173

Sato, L. (2012). Feira livre: Organização, trabalho e sociabilidade. São Paulo: Editora da Universidade de São Paulo

Sato, L. (2013). Recuperando o tempo perdido: A psicologia e o trabalho não regulado. Cadernos de Psicologia Social do Trabalho, 16 [Special issue], 99-110. https://doi.org/10.11606/issn.1981-0490. v16ispe1p99-110

Sato, L., Coutinho, M. C., \& Bernardo, M. H. (2017). A perspectiva da psicologia social do trabalho. In M. C. Coutinho, M. H. Bernardo, \& L. Sato (Orgs.), Psicologia social do trabalho (pp. 11-24). Petrópolis, RJ: Vozes. 
Silverman, D. (2009). Interpretação de dados qualitativos: Métodos para análise de entrevistas, textos e interações. Porto Alegre: Artmed.

Souza, M. \& Bustos, A. (2017). El comercio informal de calle en las comunas Santiago y Concepción. Revista Urbano, $n^{\circ} 35,58-73$. https://doi.org/10.22320/0718 3607.2017 .20 .35 .05

Xavier, D., Falcão, J. T., \& Torres, C. (2015). Caracterização da atividade laboral de trabalhadores informais em praia de Natal (RN) - Brasil. Cadernos de Psicologia Social do Trabalho, 18(1), 29-45. https://doi. org/10.11606/issn.1981-0490.v18i1p29-45

\section{Renata Guimarães de Carvalho}

Doutora em Psicologia pela Universidade de Fortaleza (Unifor, Fortaleza, CE, Brasil), professora da Universidade Federal do Ceará (UFC) em Sobral, CE, Brasil.

\section{Regina Heloisa Maciel}

Doutora em Psicologia pela Universidade de São Paulo (USP, São Paulo, SP, Brasil), professora da Universidade de Fortaleza (Unifor) em Fortaleza, CE, Brasil.

\section{Tereza Gláucia Rocha Matos}

Doutora em Psicologia pela Universitat de Barcelona (UB, Barcelona, Espanha), professora da Universidade de Fortaleza (Unifor) em Fortaleza, CE, Brasil.

\section{Cássio Adriano Braz de Aquino}

Doutor em Psicologia Social pela Universidad Complutense (UCM, Madrid, Espanha), professor da Universidade Federal do Ceará (UFC) em Fortaleza, CE, Brasil.

\section{Endereço para correspondência}

Renata Guimarães de Carvalho

Universidade Federal do Ceará

Rua Coronel Estanislau Frota, 138, curso de Psicologia, Campus Mucambinho.

Centro 62010-560

Sobral, CE, Brasil 